\title{
Assortative Marriage and the Effects of Government Homecare Subsidy Programs on Gender Wage and Participation Inequality*
}

\author{
David Bjerk \\ Assistant Professor \\ Seungjin Han \\ McMaster University \\ Assistant Professor \\ and RAND Corp. \\ McMaster University
}

September 6, 2006

\begin{abstract}
We develop a model of the labor market where firms incur an adjustment cost when one of their workers quits, and males and females form households assortatively by skill. We show how this environment can lead to an economy where females earn less and drop out more frequently than equally skilled males in equilibrium, even when males and females constitute ex-ante identical populations. We then examine how different government homecare subsidy schemes may affect such gender inequality in the labor market. We show that the effect of government homecare subsidy schemes on gender inequality depends crucially on the form in which the subsidy is given and to whom it is allocated.
\end{abstract}

*JEL codes H42, H24, J71, J16, J13. Keywords: Gender Inequality, Discrimination, Subsidized Childcare. David Bjerk: RAND Corp., 1776 Main St., P.O. Box 2138, Santa Monica, CA 90407, email: bjerkd@mcmaster.ca. Seungjin Han: Kenneth Taylor Hall, Room 421, Department of Economics, McMaster University, 1280 Main Street West, Hamilton, Ontario, Canada, L8S 4M4, email: hansj@mcmaster.ca. We are very grateful to Co-Editor, Thomas Piketty, and two anonymous referees for their thoughtful suggestions and comments on the earlier version of the paper. We also thank seminar participants at Queen's University, RAND, Simon Fraser University, the 2005 Canadian Economic Theory Conference and the 2005 Canadian Public Economics Group meetings for their helpful comments. We both thankfully acknowledge the financial support from SSHRC. 


\section{Introduction}

It is well documented that working women earn lower wages than working men, and that women have substantially lower labor force participation rates than men. ${ }^{1}$ Moreover, these gender differences even appear to hold at the highest skill levels of the labor market. For example, Wood, Corcoran, and Courant (1993) find that even in the very highly select sample of University of Michigan Law School graduates, the ratio of female to male earnings for working lawyers fifteen years out of law school is roughly 0.61, and female lawyers spent significantly more of their time not working to care for children and/or working only part-time than their male counterparts. In this paper, we propose a new model describing how such inequality can arise as a result of household decisionmaking with respect to how to supply necessary homecare. We then discuss how such inequality may be affected by different types of government homecare subsidy programs.

Earlier theoretical research on gender inequality (Becker, 1981, 1985; Lazear and Rosen, 1990) primarily examined how intrinsic gender differences in preferences or skills, even if quite small, could lead to large differences in behavior and labor market outcomes across genders. However, more recent literature examines how gender inequality can arise in equilibrium through self-fulfilling expectations, even when there are no ex-ante differences between men and women. For example, in Francois (1998), the labor market is divided into two types of jobs - those paying piece rates, and those paying efficiency wages that ensure workers do not shirk. He shows that if one, and only one member of a household has an efficiency wage job, then such households find it optimal for the lower paid household member to work less in the labor market but supply more homecare services in return for more monetary transfers from the higher paid household member. This means that if each firm believes other firms do not hire females to the efficiency wage jobs, it also finds it optimal to not hire females to an efficiency wage job, as by doing so, it can ensure that it will never be the case that more than one household member has a high-paying efficiency wage job, which increases the cost of losing that high-paying job, meaning it can offer a lower efficiency wage and

\footnotetext{
${ }^{1}$ There is a large empirical literature reinforcing this basic point that there exists substantial gender differences in wage and labor market participation both across time and across countries. Other examples include Corcoran and Duncan (1979), the papers contained in Layard and Mincer (1985), Goldin and Polacheck (1987), O'Neill and Polachek (1993), Kuhn and Weinberger (2004).
} 
still ensure optimal effort.

Subsequently, Lommerud and Vagstad (2000) develop a model showing that if firms expect that females do more household work at the expense of effort in the workplace than do males, firms may impose tougher promotion standards on women than men, which can cause firm expectations to be selffulfilling in equilibrium. Albanesi and Olivetti (2006) explore how incentive problems can amplify gender differences in earnings due to gender differences in time spent on home production, which in turn can also lead to self-fulfilling feedback mechanism. ${ }^{2}$ Similar to Lommerud and Vagstad (2000), Albanesi and Olivetti (2006), and especially Francois (1998), this paper develops a simple model for the competitive labor market where males and females form households that share both resources and homecare requirements, and gender inequality arises as a result of a self-fulfilling equilibrium. However, the underlying mechanisms that cause the gender inequality to arise in our model differ from those in these other papers. Moreover, also similar to Francois (1998), we examine how government provision of homecare subsidies may affect gender labor market inequality. However, while such subsidies necessarily decrease gender inequality in the labor market in Francois' model, the effects of such subsidies are more complicated in our model presented below.

In our model, men and women form households, where the total income earned by the household is shared among the two members and either household member has the option of withdrawing from the labor market in order to specialize in homecare activities (e.g. raising of children). In the environment we examine, individuals differ in their labor market productivity, but the distribution of labor market productivity is identical between males and females. After joining the labor market, males and females form households through assortative matching - where the most productive male workers form households with the most productive female workers and so on down.

Households then differ in their required amount of homecare, reflecting the notion that some households have more children, have children or other relatives who turn out to have special needs, or simply demand higher quality childcare. After forming a household and learning their required amount of homecare, each household must decide whether both members should keep working and then purchase their required homecare in the marketplace, or

\footnotetext{
${ }^{2}$ Also see Engineer and Welling (1999) for a potential coordination problem in the marriage market due to the timing of human capital accumulation.
} 
whether one member should drop out of the labor market and supply this required homecare internally. Employers are able to perfectly observe each worker's productivity, but not each workers' household's required amount of homecare. The key assumption is that firms also have to incur an adjustment cost if one of their hired workers subsequently chooses to leave the labor market (e.g. there exist hiring and recruiting costs, training costs, and lost firm specific human capital). Given this cost, the expected value to a firm for hiring a worker of any given productivity level will decrease in the firm's belief regarding whether that worker will subsequently leave the labor market sometime after being hired. Therefore, if firms believe that females are more likely to leave the labor market than equally skilled males, they will pay females less than equally skilled males. Such pay differentials across genders will then cause firms' beliefs to be confirmed in equilibrium, since the lower wage paid to females compared to males at any given skill level will make it optimal for households to choose the female member to exit the labor market if the household's required homecare turns out to be sufficiently high.

Given that a key source of the gender wage and labor market participation inequality that arises in this model is the cost of purchasing homecare services from the market, a natural question to ask is how gender inequality in this environment will be affected if the government chooses to provide or otherwise subsidize homecare services to some or all households. The second part of the paper looks at this question with respect to a variety of possible homecare subsidy schemes. The results of this analysis suggest that government provision of homecare subsidies will generally not be able to eradicate gender wage and participation inequality, and moreover, some reasonable subsidy schemes can very plausibly lead to increases in wage and participation inequality between equally skilled workers of different genders. Intuitively, government subsidy of homecare services will not generally alter each household's decision regarding who should stay home if homecare requirements, after accounting for the government subsidy, still turn out to be high. Moreover, while government subsidy of homecare benefits may or may not increase the incentive for females to stay in the labor market (depending on whether such subsidies are given only to dual-career households or to all households with significant required homecare), the taxes on labor earnings required to pay for these homecare subsidies will generally decrease the incentive for females to stay in the labor market. If the negative labor supply incentive associated with the taxes on labor earnings outweigh any increased participation incentive due to the structure of the subsidy, females 
will drop out of the labor market at higher rates, which will further increase the gender wage and participation gap. ${ }^{3}$

In general it is not trivial to see the net effect of government subsidy of homecare services on gender wage and participation inequality in this environment, as it depends on how the government of homecare subsidy program is structured, the distributions of workers' productivities, and the distribution of required homecare across households. However, we show that if the average value of worker productivity is higher than the average cost of purchasing the required childcare, then an in-kind childcare subsidy given only to dual-career households will unambiguously reduce gender wage and participation inequality in our environment.

\section{Model}

Say society consists of a continuum of individuals, where individuals are each characterized by their gender $s$ and type $x$. Let $\{m, f\}$ be the set of genders, where $m$ indicates male and $f$ indicates female. An individual's type represents his or her productivity in the labor market. Let $[\underline{x}, \bar{x}] \subset \mathbb{R}_{+}$ be the set of all feasible types for both males and females. Assume males and females are distributed identically across the same type distribution $G$, where the total measure of males (females) is normalized to one: $G([\underline{x}, \bar{x}])=1$. After joining the labor market, assume that males and females form households consisting of one male and one female, where these households are formed assortatively, meaning households consist of a male and a female of the same type $x$.

By working, assume an individual pays a utility cost of $e$ representing the lost leisure time associated with time spent working. Furthermore, assume that once a household is formed, a fraction $\rho \in(0,1)$ of households have children, meaning they must supply some amount of required childcare. This required childcare can either be purchased in the market, or supplied privately by one of the household members. We assume that households with children can differ in the amount of childcare they require, which can either

\footnotetext{
${ }^{3}$ Francois (1998) examined the government provision of homecare subsidy in a model with a limited number of firms and the frictions in the labor market leave positive profits in equilibrium. This meant that in his environment, the government was able to finance teh childcare subsidy only by the taxes on the firm's profits not worker earnings. More discussion follows in Section 5.
} 
be due to having more kids, having kids with special needs, or preferring more intensive childcare services. This heterogeneity in required childcare is assumed to manifest itself in the amount a household must pay to purchase their required childcare in the marketplace. Specifically, the cost to a household of purchasing their required childcare in the marketplace is given by $\eta \geq e$, where $\eta$ is a random variable drawn from a increasing and continuous probability distribution function $F$ on $[e, \infty)$. The key assumption, however, is that if a household member supplies the required childcare him or herself, he or she again pays a cost of $e$, or lose the same amount of leisure as if he or she had worked, regardless of the required amount of childcare. Intuitively, an individual must give up his or her day of free time if he or she works or if he or she stays home to provide childcare, and moreover, there are strong economies of scale in privately provided childcare - an individual gives up the same amount of leisure by taking care of one child as if he or she was took care of several children or took care of children with special needs. Note also that the assumption that $\eta \geq e$ implies the utility cost to privately providing childcare is always "cheaper" than purchasing it in the market, implying $F(e)=0 .{ }^{4}$

Households make decisions to maximize household utility, where household utility is a linear function of total household earnings minus any costs of purchased childcare and the utility of any leisure given up for work or privately providing childcare. Therefore, if we let $w_{m}$ denote the money the male member of the household can earn in the labor market and let $w_{f}$ denote the amount of money the female member of the household can earn in the labor market, then household utility will equal the following. For households who turn out not to have children, household utility equals $w_{m}+w_{f}-e-e$ if both members work, $w_{m}-e$ if only the male works, and $w_{m}-e$ if only the female works. Alternatively, for those households who have children, household utility equals $w_{m}+w_{f}-e-e-\eta$ if both members work, $w_{m}-e-e$ if the male member works and the female member provides childcare, and $w_{f}-e-e$ if the female member works and the male provides childcare. ${ }^{5}$

\footnotetext{
${ }^{4}$ We can easily modify the model to allow the time cost of supplying childcare to be less than the time cost of working. Doing so does not change any results of the paper, but does require us to introduce and carry around the extra parameter, and therefore we do not do so.

${ }^{5}$ There is a large literature on intra-household bargaining. The maximizing household net earnings preferences we assume in this paper are directly consistent with either household common preferences (Samuelson, 1956; Becker, 1981) or with households choosing
} 
Firms compete for workers in a competitive labor market. Moreover, firms can observe each worker's skill type and gender, but not whether each worker has children or the costs associated with purchasing the required childcare for these children. Firms hire workers by promising them a payment of $w$, where $w \geq 0$. When a firm hires a type- $x$ worker and the worker stays and works for the firm for a payment of $w$, the firm incurs a profit of $x-w$. However, if the firm hires a type- $x$ worker, but that worker subsequently quits, the firm doesn't have to pay the worker, but the worker doesn't produce anything and the firm must incur an adjustment cost of $q(x)>0$ for any $x \in[\underline{x}, \bar{x}] .{ }^{6}$ We also assume there is limited liability, meaning firms cannot force workers who quit to subsequently pay this adjustment cost that result from this quitting.

The timing unfolds as follows. Firms randomly meet workers and observe their gender and type. Each worker then receives simultaneous wage offers from firms. Each worker decides which offer, if any, to accept. Households are then formed between males and females assortatively in $x$, after which a household learns the amount of childcare it is required to provide. Given this required childcare, each household decides whether both members should keep working and purchase this required childcare or whether one member should quit the labor market and provide childcare internally. Individuals who stay in the labor force produce output for their firm and are subsequently paid by their firm according to the agreed contract. Since males and females form households after joining the labor market and the labor market is large, we assume that firms do not know who their employees marry at the time contracts are formed.

Finally, assume the lowest skill type is such that $(1-\rho)(x-e)-\rho q(x)>0$ for all $x \in[\underline{x}, \bar{x}]$. This condition assures that it is possible for every female worker to find employment in equilibrium. Intuitively, this condition amounts to assuming that even the lowest skilled workers are still moderately productive, and that the adjustment costs associated with a worker quitting do not become prohibitively large even for very high skilled workers. We can derive an equilibrium where these conditions are violated, however, in such an equilibrium, some female workers would be completely blocked from joining the labor market as employers would not hire them even at a wage of zero.

allocations through cooperative bargaining (McElroy and Horney, 1981; McElroy, 1990; Chiappori, 1992).

${ }^{6}$ As alluded to in the introduction, $q(x)$ is assumed to capture the "quasi-fixed" costs of labor (Oi, 1962), including such things as recruiting and hiring costs, as well as the costs required to train a new worker and lost institutional knowledge. 


\section{Discriminatory Equilibrium}

Given the set-up above, optimal behavior for each individual with respect to which offer, if any, he or she should accept is very simple to characterize given it is made before required childcare is realized. Essentially, an individual should accept the highest paying offer he or she receives, as long as that offer is greater than or equal to $e$, or greater than the value of the leisure time he or she has to give up in order to work. If the maximum offer an individual receives is below $e$, the individual should reject all offers.

Let us next consider each household's optimal decision rule concerning labor market participation subsequent to household formation. Given the utility functions specified above, this decision is also relatively straightforward. In households who don't end up having children, any individual who accepted a job offer should continue working after forming a household. In households who end up having children, each household's optimal decision rule is as follows: (a) If only one member accepted a job, the member who accepted the job should continue working after forming a household, while the other member should provide required childcare. (b) If both the male and female household members accepted jobs and earn the same wage $\left(w_{m}=w_{f}=\bar{w}\right)$, then both keep working and purchase required childcare if $\bar{w} \geq \eta$, but either the male or female household member should drop out of the labor market and privately provide required childcare if $\bar{w}<\eta$. (c) If both the male and female household members accepted jobs but the female (the male) in the household earns a lower wage than her (his) spouse, then the male (the female) should stay in the labor market, while the female (the male) should stay in the labor market and purchase required childcare if $w_{f} \geq \eta\left(w_{m} \geq \eta\right)$, but drop out and internally supply required childcare $w_{f}<\eta \quad\left(w_{m}<\eta\right)$.

Now let us consider a firm's problem. After observing a worker's type $x$ and gender $s$, say it believes that the worker will quit the job with probability $\mu_{s}(x, w)$ given any wage payment level $w$. Given beliefs $\mu=\left(\mu_{m}, \mu_{f}\right)$, a firm's expected profit associated with hiring a gender- $s$ and type- $x$ worker at a wage $w$ is

$$
\pi=\left(1-\mu_{s}(x, w)\right)(x-w)-\mu_{s}(x, w) q(x) .
$$

A firm wants to maximize expected profits. To do so, a firm's strategy consists of a pair of wage payment functions, one for each gender, that maps a worker's type to a wage offer. Specifically, a wage function offered to gender- 
$s$ workers is denoted $w_{s}(x)$. For simplicity, we assume that there are two competing firms for each worker. This is enough to generate a competitive outcome. Each worker's choice decision, each household's labor market participation decision for both members, the two firms' wage strategies $\left(w_{m}^{*}, w_{f}^{*}\right)$, and the firms' beliefs $\mu^{*}$ constitute a perfect Bayesian equilibrium (PBE) if (a) each household follows the optimal labor market participation decision rule and each worker behaves optimally with respect to choosing an offer, (b) $\left(w_{m}^{*}, w_{f}^{*}\right)$ is a Nash equilibrium of the two firms' simultaneous-move wage offer game given $\mu^{*}$, and (c) $\mu^{*}$ is derived from the worker's optimal decisions using Bayes' rule whenever possible. Moreover, we focus on the existence of a discriminatory PBE where females are paid less than equally skilled males. ${ }^{7}$ This leads to Proposition 1.

Proposition 1 There exists a discriminatory PBE such that all firms offer the same wage to workers of the same type and gender, denoted by $w_{s}^{*}(x)$ for a worker of type- $x$ and gender $s$, where $(i) w_{m}^{*}(x)=x$, (ii) $\mu_{m}^{*}\left(x, w_{m}^{*}(x)\right)=$ 0, $\quad$ (iii) $w_{f}^{*}(x)=x-g^{*}(x)$, with $g^{*}(x)>0$ for all $x \in[\underline{x}, \bar{x}]$, and (iv) $\mu_{f}^{*}\left(x, w_{f}^{*}(x)\right)=\rho\left(1-F\left(w_{f}^{*}(x)\right)\right)>0$

While the details to the proof of Proposition 1 can be found in the Appendix, the basic idea is relatively straightforward. In the competitive labor market, equilibrium profits for any firm equal zero. Hence, setting equation (1) equal to zero and re-arranging, we get the following expression that must hold for each firm's wage offer in equilibrium for a worker of type- $x$ and gender-s given beliefs $\mu_{s}$,

$$
w_{s}=x-\frac{\mu_{s}}{1-\mu_{s}} q(x) .
$$

If firms believe males will not drop out of the labor force in equilibrium, then $\mu_{m}^{*}\left(x, w_{m}^{*}(x)\right)=0$ for all $x \in[\underline{x}, \bar{x}]$, and the above zero-profit condition directly implies that males will be offered a wage equal to their productivity in equilibrium. On the other hand, if firms also believe that after forming

\footnotetext{
${ }^{7}$ In general, the notion of a self-fulfilling equilibrium tends to generate multiple equilibria. For examples, see Coate and Loury's model (1993) of racial discrimination and Mailath and Postlewaite's model (2004) of social norms. This model is no exception. Given we assume females and males come from identical skill distributions, there will also be a PBE where males are paid less than equally skilled females, as well as a pooling PBE where males and females are paid equally.
} 
a household females will drop out of the labor market with some positive probability in equilibrium, then $\mu_{f}^{*}\left(x, w_{f}^{*}(x)\right)>0$. Equation (2) shows that if this is the case, then a female of type- $x$ will be offered a salary less than $x$, meaning females will be paid less than their equally skilled spouses.

Given males are paid more than their spouses, then according to the optimal labor force participation rule, males will indeed always work, which confirms firm beliefs. Alternatively, females will drop out of the labor market whenever $w_{f}<\eta$. Therefore, for any given wage offered to type- $x$ females such that $w_{f}<x$, a fraction $\rho\left[1-F\left(w_{f}\right)\right]$ of such females will drop out of the labor market after forming a household. Since in equilibrium firms' beliefs must correspond to the truth, it must be the case that $\mu_{f}^{*}\left(x, w_{f}^{*}(x)\right)=$ $\rho\left[1-F\left(w_{f}^{*}(x)\right)\right]$. Therefore, for any given type- $x, w_{f}^{*}(x)$ must be such that

$$
w_{f}^{*}(x)=x-\frac{\rho\left[1-F\left(w_{f}^{*}(x)\right)\right]}{1-\rho\left[1-F\left(w_{f}^{*}(x)\right)\right]} q(x) .
$$

Equation (3) reveals the form for the function $g^{*}(x)$ presented in Proposition 1 .

Proposition 1 implies that even though males and females constitute exante identical populations, there exists a PBE where females earn less and are more likely to drop of the labor market than equally skilled males. Parts (i) and (iii) of Proposition 1 capture the wage inequality between equally skilled male and female workers in such a PBE. It is interesting to note that the female worker's equilibrium wage is strictly less than the male worker's equilibrium wage at every skill level even though wage payments are wholly contingent on whether or not the worker quits. This occurs because a worker has limited liability, so the firm cannot ask a worker who quits the job to pay the firm's adjustment costs associated with her quitting. This means the gender wage gap $g^{*}(x)$ is basically the equilibrium risk premium that type- $x$ females have to pay because of their higher equilibrium probability of subsequently dropping out of the labor market after forming a household.

\section{The Effects of Childcare Subsidies on Gen- der Inequality}

In recent years, several "family oriented" policies have been either implemented or proposed in both the U.S. and Canada. For example, in the 
Working Families Tax Relief Act of 2004, the U.S. Federal Government introduced an annual $\$ 1000$ tax credit for each child under the age of 17 in the household. Similarly, in 2006, the Federal Government of Canada introduced the Universal Child Care Benefit, which provides monthly cash payments of $\$ 100$ for each with a child under age six in the household. Relatedly, government provided universal pre-school was recently proposed in a ballot measure in California, and a $\$ 5 /$ day government subsidized childcare program was implemented in Quebec in 1997. While these policies have certainly not been solely aimed at lessening gender inequality in the labor market, several researchers and policy makers have suggested that such government provision of childcare subsidies may be "potentially appealing instruments for achieving a degree of (gender) equality in the labour market" (Cleveland, Gunderson, and Hyatt, 1996). Indeed, given the key role played by childcare costs in generating gender wage and participation inequality in the model developed above, a natural question to ask is how such gender inequality would be affected by the implementation of different types of childcare subsidy programs.

Motivated by the types of childcare subsidies discussed above, we will analyze the effect of two basic government programs on gender labor market inequality - a cash transfer approximating a child tax credit and an in-kind benefit approximating government provided childcare. A key component of the analysis to follow however, is that in order to implement either of these programs, the government must raise the tax revenue required to fund such programs though proportional taxes on earnings.

\section{(a) Cash Benefit to those with Positive Homecare Requirements}

Suppose the government subsidized homecare requirements by providing a cash benefit $b$ to every household with positive childcare requirements funded by a proportional tax $t$ on the earnings of each worker. Finding the discriminatory PBE given a homecare provision scheme such as this is actually very similar to finding the discriminatory PBE in the absence of any government provision program as done in Proposition 1. This leads to Proposition 2 (once again, see Appendix for proof).

Proposition 2 For any proportional tax $t$ on labor earnings, there exists a discriminatory PBE with a budget balancing cash benefit $b$ given to every household with a positive childcare requirement such that all firms offer the same wage to workers of the same type and gender, and for any given type-x: 
(i) $w_{m}^{*}(x, t)=x$, (ii) $\mu_{m}^{*}\left(x, w_{m}^{*}(x, t)\right)=0$, (iii) $w_{f}^{*}(x, t)=x-\widetilde{g}(x, t)$, where $\widetilde{g}(x, t)>0$ for all $x \in[\underline{x}, \bar{x}]$, and $(i v) \mu_{f}^{*}\left(x, w_{f}^{*}(x, t)\right)=1-F\left((1-t) w_{f}^{*}(x, t)\right)$.

The intuition for the above Proposition is as follows. Once again, it will be true that firms make zero expected profits in equilibrium. Therefore, as above, for a worker of type- $x$ and gender- $s$, each firm's equilibrium wage offer must be such that $w_{s}=x-\left[\mu_{s} q(x) /\left(1-\mu_{s}\right)\right]$. Also like before, if firms believe males will not drop out of the labor force (meaning $\mu_{m}=0$ ), then males will be offered a wage equal to their productivity type- $x$. However, females will continue to be paid less than their equally skilled spouses if firms still believe females will drop out of the labor market with some positive probability. Therefore, given a proportional tax $t$ and a cash benefit of $b$ that is allocated to a household regardless of whether both members work or not, it will be optimal for a type- $x$ female member of the household to stay in the labor market if and only if $(1-t) w_{f}+b-e-\eta \geq b-e$, or equivalently, if and only if $(1-t) w_{f} \geq \eta$. Therefore, for a given wage $w_{f}<x$, a fraction $\rho\left[1-F\left((1-t) w_{f}\right)\right]$ of females of type- $x$ will drop out of the labor market with proportional taxation.

Given that firms' equilibrium beliefs must correspond to the truth, it must be true that $\mu_{f}^{*}(x, w)=\rho[1-F((1-t) w)]$. Therefore, for any given type- $x$ and tax $t$, the equilibrium wage for females must be such that

$$
w_{f}^{*}(x, t)=x-\frac{\rho\left[1-F\left((1-t) w_{f}^{*}(x, t)\right)\right]}{1-\rho\left[1-F\left((1-t) w_{f}^{*}(x, t)\right)\right]} q(x) .
$$

Similar to before, in the discriminatory PBE where females earn less than males, the equilibrium wage $w_{f}^{*}(x, t)$ for type- $x$ females under proportional taxation must solve equation (4) given any $t$. Unlike before however, to fully describe equilibrium wages for females, we also must determine the budget balancing cash benefit $b$ that can be maintained for any given $t$. In particular, with a proportional tax $t$, the total expected tax revenue will equal

$$
r(t)=\int_{\underline{x}}^{\bar{x}} t x+t(1-\rho) w_{f}^{*}(x, t)+\rho t w_{f}^{*}(x, t) F\left((1-t) w_{f}^{*}(x, t)\right) d G(x),
$$

Moreover, the total expected expenditure associated with any given benefit $b$ for this program is

$$
e(b)=b \rho .
$$


Therefore, under any given proportional tax $t$, a discriminatory PBE with a balanced budget for a cash benefit given to all those with positive childcare requirements can be derived by finding the $w_{f}^{*}(x, t)$ and $b$ that solves equation (4) while simultaneously equating $r(t)$ to $e(b)$.

The above proposition reveals that government provision of cash childcare benefits to all households with positive childcare requirements will not necessarily eradicate wage and participation inequality across equally skilled workers of different genders, as the discriminatory equilibrium still exists. The following Corollary states an even stronger result.

Corollary 1 A government provided cash benefit given to all households with positive homecare requirements that is funded using a proportional tax on earnings will unambiguously increase wage and participation inequality between equally skilled male and female workers in the discriminatory equilibrium where males earn more than equally skilled females.

The intuition for Corollary 1 comes from the condition required for a female to stay in the labor market. In particular, recall that in the absence of any government subsidy scheme, a female will only stay in the labor market if $w_{f} \geq \eta$. However, as shown above, with a government provided cash benefit to households with positive homecare requirements that is funded via proportional taxation, a female will only stay in the labor market if (1$t) w_{f} \geq \eta$. Note that for any given $w_{f}$, the latter condition for working is more restrictive than the condition for working in the absence of any government provision. This highlights the fact that when a homecare benefit is given regardless of whether or not both household members work, there is no new incentive for the household to choose the male member to drop out or any added incentive for females to stay in the labor market. However, the tax required to pay for the government subsidy lowers the incentive for females to stay in the labor market. This lesser incentive to stay in the labor force means more females will drop out of the labor force, which in turn will further exacerbate gender wage inequality.

\section{(b) In-Kind Childcare Benefits}

We showed above that, in this environment, gender wage and participation inequality in a discriminatory equilibrium when a cash benefit is provided to all households with children is greater than in a discriminatory equilibrium where no homecare subsidies are provided. Here we examine how 
gender inequality may be affected if the government provision is made more restrictive, namely by the providing childcare subsidy in-kind.

Specifically, let us consider a program that provides a fraction $s$ of each household's required amount of childcare, where once again this program is funded by a proportional tax $t$ on earnings. This program has two distinct effects. First, for households where both members work, it lessens the cost of purchasing their required childcare from $\eta$ to $(1-s) \eta$. Second, for households where only one member works, it lessens the amount of leisure time lost due to providing childcare by the stay-at-home parent from $e$ to $(1-s) e$. The interesting question is whether the inequality in a discriminatory equilibrium will be greater than or less than the inequality that arises in the discriminatory equilibrium without any government childcare subsidies. ${ }^{8}$ This leads to the following Corollary.

Corollary 2 A government program that offers an in-kind childcare subsidy covering a fraction s of the childcare requirements for each household and is funded via a proportional tax on earnings can increase or decrease wage and participation inequality between equally skilled male and female workers in the discriminatory equilibrium.

The intuition for Corollary 2 is the following. As discussed above, the structure of this subsidy is such that if both members of the household work, they will only have to spend $(1-s) \eta$ on childcare. Alternatively, if the female member drops out, she now only has to commit $(1-s) e$ of her time providing childcare given the government provision of childcare. Therefore, under an in-kind subsidy program funded via a proportion tax on earnings, a household where both members work will incur utility of $(1-t)\left(w_{m}+w_{f}\right)-e-e-(1-s) \eta$ for any given $w_{m}$ and $w_{f}$, while a household where only the higher paid male works will incur a utility of $(1-t) w_{m}-e-(1-s) e$. This means that under an in-kind childcare subsidy program funded via proportional taxation, a female household member will only work if $(1-t)\left(w_{m}+w_{f}\right)-e-e-(1-s) \eta \geq$ $(1-t) w_{m}-e-(1-s) e$, or equivalently, if and only if $(1-t) w_{f}-s e \geq(1-s) \eta$. The key thing to note is that since $w_{f}$ is increasing in $x$ in equilibrium, this last condition can be either more or less restrictive than the relevant condition under no program (i.e. $w_{f} \geq \eta$ ) depending on the distributions of $x$ and $\eta$ (which will affect the maximum size of $s$ for any given $t$ ) and the size of $e$.

\footnotetext{
${ }^{8}$ The existence of the discriminatory equilibrium under the in-kind childcare benefits program can be proved similarly as proved in Proposition 2.
} 


\section{(c) Restricting Benefits to Dual-Career Households Only}

An important question that remains is whether there exists any government childcare subsidy program that will unambiguously lead to lower wage and participation inequality. The answer to this question is yes. In particular, as will be shown below, the key to ensuring less wage and participation inequality in this environment is to implement a program that lowers the cost of working without increasing the benefit to staying home. Therefore, in this final section, we consider programs that give a cash benefit or an in-kind benefit to dual-career households only. ${ }^{9}$

Clearly, if dual-career households (and only dual-career households) were promised a benefit large enough to cover all of their required homecare requirements, no one would ever drop out of the labor market, and consequently there would no longer be a discriminatory equilibrium. However, in the absence of such an all encompassing subsidy plan, even a relatively restrictive benefit program that only gives childcare benefits to dual-career households will not unambiguously decrease gender wage and participation inequality in this environment. In particular, consider the following Corollary.

Corollary 3 A government program that offers a cash benefit to only dual career households with children that is funded via a proportional tax on earnings can increase or decrease wage and participation inequality between equally skilled male and female workers in the discriminatory equilibrium.

To understand the intuition for the above Corollary, once again let us compare the relevant household utility levels of having both members work versus having only the male work. If both members work, household utility will equal $(1-t)\left(w_{m}+w_{f}\right)-e-e-\eta+b$ under the cash benefit program to dual-career households. Alternatively, household utility if only the male works under the cash benefit program to dual-career households will equal $(1-t) w_{m}-e-e$. This means, the relevant condition for it to be optimal for both household members to work under the cash benefit program to dualcareer households only is $(1-t) w_{f}+b \geq \eta$. From this expression it can then be inferred that, under the cash benefit program to dual-career households only, it is possible for wage and participation inequality to go up over some

\footnotetext{
${ }^{9}$ The existence of a discriminatory equilibrium where males are paid more than equally skilled females under each childcare program can be proved similarly as existence was proved in Proposition 2.
} 
range of the $x$ distribution if the $x$ distribution has a long right-tail since equilibrium $w_{f}$ rises with $x$.

Finally, consider this last Corollary regarding a government program that offers in-kind benefits to dual-career households only.

Corollary 4 A government program that offers an in-kind childcare subsidy covering a fraction $s$ of the childcare requirements for dual-career households that is funded via a proportional tax on earnings unambiguously decreases wage and participation inequality between equally skilled male and female workers in the discriminatory equilibrium if average worker productivity exceeds the the average cost of purchasing required homecare across all households (i.e. $\int_{x}^{\bar{x}} x d G(x)>\rho \int_{e}^{\infty} \eta d F(\eta)$ ).

Intuitively, under the in-kind program restricted to dual-career households, if both members work, household utility will equal $(1-t)\left(w_{m}+w_{f}\right)-$ $e-e-(1-s) \eta$. Alternatively, under this program, if the female member quits her job and stays home for childcare, household utility will equal $(1-t) w_{m}-e-e$. Therefore, both members will work if and only if $\frac{(1-t)}{(1-s)} w_{f} \geq \eta$. As one can see, this condition is less restrictive than the one without a childcare program if $t<s$. A sufficient condition for $t$ to be less than $s$ in a balanced budget equilibrium turns out to be $\int_{\underline{x}}^{\bar{x}} x d G(x)>\rho \int_{e}^{\infty} \eta d F(\eta)$, or when the average productivity of each gender is greater than the average cost of childcare across all households.

\section{Summary and Discussion}

The model developed in the first part of this paper shows that women may get paid less and have weaker participation in the labor market than men, even without any significant differences between gender groups. We should also acknowledge however, that this model is highly stylized and may omit some important issues. For example, a worker's labor/leisure/homecare choice is obviously much more complex than the binary work/not-work structure assumed here, and households likely also differ in terms of the amount of utility "lost" by supplying their required homecare themselves (i.e. providing childcare to their own children). However, the essence of the self-fulfilling mechanism for the discriminatory equilibrium we examine would not necessarily be altered if we allowed for such greater complexity. The only necessary conditions for the results in our paper to hold are for firms to not be able 
to require workers who quit to pay for the costs associated with hiring and training a replacement, and for firms to believe females are more likely than males to quit the labor market. These beliefs, along with the existence of hiring/replacement costs, mean firms will pay females less than equally skilled males. Then, as long as similarly skilled males and females choose to marry each other, such a pay differential will mean that households will always find it optimal for the female member to supply less time to the labor market and more to internally providing required homecare when the cost of purchasing the required homecare becomes sufficiently high. This confirms firms' beliefs, giving firms no reason to change their beliefs or their discriminatory behavior.

The assumptions regarding the identical skill distributions and perfect positive assortative marriage are also quite strong. However, they were only made to keep things simple, and the existence of the discriminatory equilibrium is generally robust to some loosening of these assumptions. One way to confirm this is to note that a sufficient condition for the discriminatory equilibrium we examine to hold is simply for households to be made up of males and females who are "reasonably" close in type. To see this point more precisely, a type- $\widetilde{x}$ female worker's equilibrium wage is unique in our discriminatory equilibrium and it is equal to $\widetilde{x}-g^{*}(\widetilde{x})$. Let $x$ be the type of the spouse of a given type- $\widetilde{x}$ female, meaning the male spouse's equilibrium wage is equal to $x$. Since the low income spouse leaves the job if the household's required homecare turns out to be sufficiently high, the spouse who drops out will be the female as long as $\widetilde{x}-g^{*}(\widetilde{x})<x$. If husband's type is greater than wife's type (i.e. $\widetilde{x}<x$ ), then this condition obviously holds. More importantly, this condition shows that even if husband's type is lower than wife's type, the discriminatory equilibrium can still be supported as long as her type is not too much larger than her spouse's. This means that even if marriage is not perfectly positively assortative, or if it is, but the female skill distribution stochastically dominates the male skill distribution by a small amount, the discriminatory equilibrium we examine still exists. ${ }^{10}$

In the second part of the paper, we examined whether government homecare subsidies may provide a way of eradicating or at least diminishing gender inequality. Indeed, in the model presented in Francois (1998), such programs necessarily help lower discrimination and gender labor market inequality.

\footnotetext{
${ }^{10}$ In fact, there is considerable empirical evidence that it is relatively rare for females to marry males with substantially lower education than themselves (Qian, 1998).
} 
However, the results of our analysis showed that this will not always be the case in outside of the dual-labor market environment he examines. In particular, the positive results in Francois stem from the fact that firms earn positive profits in equilibrium in his environment, so the government is able to finance childcare subsidies by taxing firm profits not worker earnings. This means any negative labor market supply effects of taxes on labor earnings are absent in his paper. However, it is not hard to imagine that workers at least partially bear the burden of financing a government childcare subsidy especially in a highly competitive labor market. Therefore, as we argued above, the net effect of childcare subsidy programs on gender inequality is often ambiguous, and in general depends not only on the structure of the childcare subsidy program, but also on the distribution of worker's productivities and the market costs of childcare. As shown in Corollary 4, in this environment, only when a childcare subsidy is given in-kind, and restricted to dual-career households only, will gender wage and participation inequality unambiguously fall in a discriminatory equilibrium. ${ }^{11}$

In summary, we think the model we presented in this paper represents a new way of thinking about how gender wage and participation inequality can arise and persist in a competitive labor market. Moreover, the model shows how government childcare subsidies, especially those in the form of cash benefits given to all households with children such as those in the U.S. Working Families Tax Relief Act of 2004 and the Canadian Universal Child Care Benefit of 2006, can potentially increase this inequality. Therefore, when implementing a childcare subsidy program, careful consideration should be given with respect to both how and to whom the benefits will be allocated if government is concerned about gender inequality in the labor market.

\section{Appendix}

\section{Proof of Proposition 1}

To prove Proposition 1, first note that in any discriminatory PBE where females are paid less than equally skilled males, each household's optimal decision rule regarding labor participation under assortative marriage means that males will never drop out of the labor force, while females will drop out of the labor force whenever $w_{f}<\eta$. Therefore, in any such equilibrium, each firm's beliefs are $\mu_{m}^{*}(x, w)=0$ and $\mu_{f}^{*}(x, w)=\rho[1-F(w)]$ for all

\footnotetext{
${ }^{11}$ Even this result is only guaranteed if the worker's average productivity is higher than the average cost of childcare.
} 
$(x, w)$. This shows that parts (ii) and (iv) of Proposition 1 must hold in the discriminatory PBE.

Next, note that the firm's equilibrium profit by hiring any worker is zero in the competitive labor market due to the argument in Bertrand competition models. Therefore, the unique equilibrium wage for the type- $x$ male worker is $w_{m}^{*}(x)=x$ for all $x \in[\underline{x}, \bar{x}]$ given the firm's equilibrium belief $\mu_{m}^{*}(x, w)=0$. This confirms that part (i) of Proposition 1 holds in the discriminatory PBE. Applying the zero profit condition in equilibrium and plugging $\mu_{f}^{*}(x, w)=$ $\rho[1-F(w)]$ into equation (1), the equilibrium wage for the female worker of type- $x$ in the discriminatory PBE is expressed by equation (3).

Let $h(w, x)=x-\{\rho[1-F(w)] q(x) /(1-\rho[1-F(w)])\}$. Note that a wage cannot be lower than $e$ to get any workers, nor higher than $x$ for any $x$ since a firm would surely lose money if it offered a wage greater than the worker's productivity. Therefore, $h(w, x)$ is a function from $[e, x]$ into a set of real numbers. Next, note that (i) $h(e, x)>e$ due to the assumption $(1-\rho)(x-e)-\rho q(x)>0$ and (ii) $h(x, x)<x$ since we have $0<F(x)<1$ and $0<\rho<1$. Finally, $h(\cdot, x)$ is a continuous function in $w$, which implies, together with (i) and (ii), that the image of $h(w, x)$ is contained in $[e, x]$. Since $h(e, x)>e, h(x, x)<x$, and $h(\cdot, w)$ is a continuous function from $[e, x]$ into $[e, x]$, the fixed point of $h(\cdot, x)$ exists. Let $P(x)$ be the set of the fixed points of $w=h(w, x)$. By Corollary 16.51 in Aliprantis and Border (1999), $P(x)$ is a non-empty compact set. The equilibrium wage $w_{f}^{*}(x)$ is the maximal fixed point in the set $P(x)$ because the firm can otherwise find a profitable wage offer. Given an the existence of the equilibrium wage schedule for females, the wage gap between genders of any given type- $x$ is given by

$$
g^{*}(x)=\frac{\rho\left[1-F\left(w_{f}^{*}(x)\right)\right]}{1-\rho\left[1-F\left(w_{f}^{*}(x)\right)\right]} q(x) .
$$

Since $\rho\left[1-F\left(w_{f}^{*}(x)\right)\right] /\left\{1-\rho\left[1-F\left(w_{f}^{*}(x)\right)\right]\right\}$ and $q(x)$ are both positive, $g^{*}(x)>0$ at all $x \in[\underline{x}, \bar{x}]$. This proves the existence of the discriminatory $\mathrm{PBE}$, and confirms parts (i)-(iv) of Proposition 1.

\section{Proof of Proposition 2}

In the discriminatory equilibrium, the male worker's equilibrium wage is again equal to his productivity type $x$ since the firm believes that the male worker will never quit the job. However, the firm believes that the female worker may quit the job with a positive probability. Given that firms' equilibrium beliefs must correspond to the truth, it must be true that $\mu_{f}^{*}(x, w)=$ 
$\rho[1-F((1-t) w)]$ as discussed in the text. Therefore, the equilibrium wage for the female worker of type- $x$ is the maximal fixed point of equation (4). The existence of such a fixed point can be proved similarly as proved in Proposition 1. The only difference between the proof for Proposition 2 and that for Proposition 1 is that we also need to find, for any given $t$, the maximal $b$ that satisfies the balanced budget condition. As discussed in the text, the government balanced budget condition requires $r(t)=e(b)$. Using expressions (5) and (6), for any given $t$, the budget balancing cash benefit $b$ is implicitly given by finding the $w_{f}^{*}(x, t)$ at $t$ that jointly solve equation (4) and $\frac{1}{\rho} \int_{\underline{x}}^{\bar{x}} x+w_{f}^{*}(x, t) F\left((1-t) w_{f}^{*}(x, t)\right) d G(x)$.

\section{Proof of Corollary 1}

Note that $\rho[1-F(\cdot)] /\{1-\rho[1-F(\cdot)]\}$ is a decreasing function. Therefore, for each type- $x$ female worker, any proportional tax rate $t \in(0,1)$, and any $w \geq w_{f}^{*}(x)$, we have

$$
w>x-\frac{\rho[1-F((1-t) w)]}{1-\rho[1-F((1-t) w)]} q(x) .
$$

Since the equilibrium wage $w_{f}^{*}(x, t)$ for the type- $x$ female worker under the cash benefits program is the maximal wage that equates the left-hand side to the right-hand side in $(7), w_{f}^{*}(x, t)$ must be strictly less than $w_{f}^{*}(x)$ for all $x$ and all $t \in(0,1)$.

\section{Proof of Corollary 2}

Recall that the equilibrium wage for the female worker of type- $x$ without provision for homecare services is the maximal fixed point of $w=h\left(w^{\prime}, x\right)$ for all $x$. The equilibrium wage $w_{f}^{*}(x, t)$ for the female worker of type- $x$ is the maximal fixed point of $w=d\left(w^{\prime}, x, t, s\right)$ for a budget balancing $(t, s)$, where $d(w, x, t, s)$ is defined as

$$
d(w, x, t, s)=x-\frac{\rho\left[1-F\left(\frac{1-t}{1-s} w-\frac{s e}{1-s}\right)\right]}{1-\rho\left[1-F\left(\frac{1-t}{1-s} w-\frac{s e}{1-s}\right)\right]} q(x)
$$

The existence of the maximum fixed point of $w=d\left(w^{\prime}, x, t, s\right)$ can be proved similarly to Proposition 1. Given the definitions of $d(w, x, t, s)$ and $h(w, x)$, the function $d$ satisfies the following properties: for each $x$, (i) $d(w, x, t, s)<$ $h(w, x)$ if $w<s e /(s-t)$, (ii) $d(w, x, t, s)>h(w, x)$ if $w>s e /(s-t)$, and (iii) $d(w, x, t, s)=h(w, x)$ if $w=s e /(s-t)$. Let $\widetilde{x}$ be the type of the female 
worker such that $w_{f}^{*}(\widetilde{x})=s e /(s-t)$. Consider any female worker whose type $x$ is such that $w_{f}^{*}(x)>w_{f}^{*}(\widetilde{x})$. Since $w_{f}^{*}(x)>\operatorname{se} /(s-t), d\left(w_{f}^{*}(x), x, t, s\right)>$ $h\left(w_{f}^{*}(x), x\right)=w_{f}^{*}(x)$. Therefore, there exists a fixed point of $w=d(w, x, t, s)$ in the range $\left(w_{f}^{*}(x), x\right]$, which implies that $w_{f}^{*}(x, t)$ is greater than $w_{f}^{*}(x)$. Now, consider any female worker whose type $x$ is such that $w_{f}^{*}(x) \leq w_{f}^{*}(\widetilde{x})$. Since $w_{f}^{*}(x) \leq s e /(s-t), d\left(w_{f}^{*}(x), x, t, s\right) \leq h\left(w_{f}^{*}(x), x\right)=w_{f}^{*}(x)$. However, it is not certain whether there exists $w \in\left(w_{f}^{*}(x), x\right]$ such that $d(w, x, t, s)>w$. Therefore, it is uncertain whether the equilibrium wage for the female worker whose type $x$ such that $w_{f}^{*}(x)-w_{f}^{*}(\widetilde{x})$ is positive or negative.

\section{Proof of Corollary 3}

The equilibrium wage $w_{f}^{*}(x, t)$ for the female worker of type- $x$ under the cash benefits program that gives the benefit to dual-career households only, is the maximal fixed point of $w=c\left(w^{\prime}, x, t, b\right)$ for a budget balancing $(t, b)$, where $c(w, x, t, b)$ is defined as

$$
c(w, x, t, b)=x-\frac{\rho[1-F((1-t) w+b)]}{1-\rho[1-F((1-t) w+b)]} q(x)
$$

Given the definitions of $c(w, x, t, b)$ and $h(w, x)$, the function $c$ satisfies the following properties: for each $x$, (i) $c(w, x, t, b)<h(w, x)$ if $w>b / t$, (ii) $c(w, x, t, s)>h(w, x)$ if $w<b / t$, and (iii) $c(w, x, t, b)=h(w, x)$ if $w=b / t$. Let $\widetilde{x}$ be the type of the female worker such that $w_{f}^{*}(\widetilde{x})=b / t$. The properties of the function $c$ makes $w_{f}^{*}(\widetilde{x}, t)=w_{f}^{*}(\widetilde{x})$.Consider any female worker whose type $x$ is such that $w_{f}^{*}(x)>w_{f}^{*}(\widetilde{x})$. Since $w_{f}^{*}(x)>b / t$ and $w_{f}^{*}(x)$ is the maximum fixed point of $w=h\left(w^{\prime}, x\right)$, we have $c(w, x, t, b)<h(w, x)<w$ for all $w \in\left(w_{f}^{*}(x), x\right]$. Therefore, the equilibrium wage $w_{f}^{*}(x, t)$ must be less than $w_{f}^{*}(x)$ for these types- $x$. Now, consider any female worker whose type $x$ is such that $w_{f}^{*}(x)<w_{f}^{*}(\widetilde{x})$. Since $w_{f}^{*}(x)>b / t$ and $w_{f}^{*}(x)$ is the maximum fixed point of $w=h\left(w^{\prime}, x\right)$, we have $c\left(w_{f}^{*}(x), x, t, b\right)>h\left(w_{f}^{*}(x), x\right)=w_{f}^{*}(x)$. This implies that her equilibrium wage $w_{f}^{*}(x, t)$ must be higher than $w_{f}^{*}(x)$ for these types- $x$. Therefore, $w_{f}^{*}(x)-w_{f}^{*}(\widetilde{x})$ can be positive or negative depending on $x$.

\section{Proof of Corollary 4}

The equilibrium wage $w_{f}^{*}(x, t)$ for the female worker of type- $x$ under the in-kind program for dual career households is the maximal fixed point of 
$w=z\left(w^{\prime}, x, t, s\right)$, where $z(w, x, t, s)$ is defined as

$$
z(w, x, t, s)=x-\frac{\rho\left[1-F\left(\frac{1-t}{1-s} w\right)\right]}{1-\rho\left[1-F\left(\frac{1-t}{1-s} w\right)\right]} q(x)
$$

If $t<s$, we have $z(w, x, t, s)>h(w, x)$ for all $(w, x)$, which implies that $w_{f}^{*}(x, t)>w_{f}^{*}(x)$ for all $x$. Under the in-kind childcare subsidy program where the subsidy is given to dual-career households only, the total expenditure, $e(s)$, and the total revenue, $r(t)$, are

$$
\begin{gathered}
e(s)=\rho \int_{\underline{x}}^{\bar{x}} \int_{\frac{1-t}{1-s} w_{f}^{*}(x, t)}^{\infty} s \eta d F(\eta) d G(x) \\
r(t)=\int_{\underline{x}}^{\bar{x}} t x+t w_{f}^{*}(x, t) F\left((1-t) w_{f}^{*}(x, t)\right) d G(x)
\end{gathered}
$$

From the budget balancing condition, we have

$$
\frac{t}{s}=\frac{\rho \int_{\underline{x}}^{\bar{x}} \int_{\frac{1-t}{1-s} w_{f}^{*}(x, t)}^{\infty} \eta d F(\eta) d G(x)}{\int_{\underline{x}}^{\bar{x}} x+w_{f}^{*}(x, t) F\left((1-t) w_{f}^{*}(x, t)\right) d G(x)}<\frac{\rho \int_{e}^{\infty} \eta d F(\eta)}{\int_{\underline{x}}^{\bar{x}} x d G(x)}
$$

If $\int_{\underline{x}}^{\bar{x}} x d G(x)>\rho \int_{e}^{\infty} \eta d F(\eta)$, we have $t<s$.

\section{References}

[1] Albanesi, Stefania and Claudia Olivetti, 2006. "Home Production, Market Production and the Gender Wage Gap: Incentives and Expections." CEPR DP 4984.

[2] Aliprantis, Charalambos D. and Kim C. Border. 1999. Infinite Dimensional Analysis: A Hitchhiker's Guide, Springer

[3] Becker, Gary S. 1981. A Treatise on the Family. Cambridge, Mass: Harvard University Press.

[4] —. 1985. "Human Capital, Effort, and the Sexual Division of Labor." Journal of Labor Economics 3: S33-S58.

[5] Coate, Stephen and Glenn Loury. 1993. "Will Affirmative Action Eliminate Negative Stereotypes?" American Economic Review 83: 1220-40. 
[6] Chiappori, Pierre-Andre. 1992. "Collective Labor Supply and Welfare." Journal of Political Economy 100:437-67.

[7] Cleveland, Gordon, Morley Gunderson, and Douglas Hyatt. 1996. "Child Care Costs and the Employment Decision of Women: Canadian Evidence." The Canadian Journal of Economics 29: 132-151.

[8] Engineer, Merwan and Linda Welling. 1999. "Human Capital, True Love, and Gender Roles: Is Sex Destiny?" Journal of Economic Behavior \& Organization 40: 155-178

[9] Francois, Patrick. 1998. "Gender Discrimination Without Gender Difference: Theory and Policy Responses." Journal of Public Economics 68: $1-32$.

[10] Goldin, Claudia and Solomon Polachek. 1987. "Residual Differences by Sex: Perspectives on the Gender Gap in Earnings." American Economic Review Papers and Proceedings 77: 143-151.

[11] Kuhn, Peter and Katherine Weinberger. 2004. "The Narrowing of the U.S. Gender Earnings Gap, 1959-1999: A Cohort-Based Analysis." manuscript, UC-Santa Barbara.

[12] Layard, Richard and Jacob Mincer. 1985. "Trends in Women's Work, Education, and Family Building." Journal of Labor Economics 3: No. 1 Pt. 2.

[13] Lazear, Edward P., and Sherwin Rosen. 1990. "Male-Famale Wage Differentials in Job Ladders." Journal of Labor Economics 8: S106-S123.

[14] Lommerud, Kjell E. and Steinar Vagstad. 2000 "Mommy Tracks and Public Policy: On Self-fulling Prophecies and Gender Gaps in Promotion." forthcoming, Journal of Labor Economics.

[15] Mailath, George, and Andrew Postlewaite. 2004. "Social Assets." PIER Working paper 04-025, University of Pennsylvania.

[16] McElroy, Margorie. 1990. "The Empirical Content of Nash Bargained Household Behavior." Journal of Human Resources 25: 559-83.

[17] McElroy, Margorie and Mary Jean Horney. 1981. "Nash Bargained Household Decisions." International Economic Review. 22:333-49. 
[18] Oi, Walter. 1962. "Labor as a Quasi-fixed Factor." Journal of Political Economy, 70 (Dec.): 538-555.

[19] O'Neill, June, and Solomon Polachek. 1993. "Why the Gender Gap in Wages Narrowed in the 1980s". Journal of Labor Economics 11: 205-228.

[20] Qian, Zenchao. 1998. "Changes in Assortative Mating: The Impact of Age and Education, 1970-1990." Demography 35(3): 279-292.

[21] Samuelson, Paul. 1956. "Social Indifference Curves." Quarterly Journal of Economics 70: 1-22.

[22] Wood, Robert G., Mary E. Corcoran, and Paul N. Courant. 1993. "Pay Differences Among the Highly Paid: The Male-Female Earnings Gap in Lawyer's Salaries." Journal of Labor Economics 11: 417-441. 